\title{
The Molecular Approach behind Biotechnological Common Problems
}

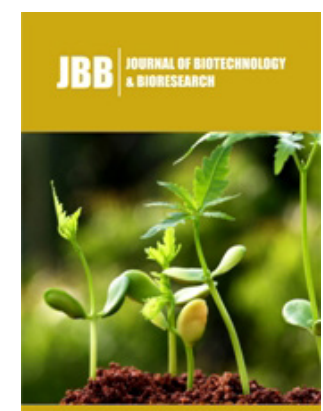

*Corresponding author: Jorge A De los Santos, Department of Animal Science, Madison University, Wisconsin, USA

Submission: 侮毕 October 30, 2019

Published: 海 November 6, 2019

Volume 2 - Issue 2

How to cite this article: Jorge A De los Santos. The Molecular Approach behind Biotechnological Common Problems. J Biotech Biores.2(2). JBB.000535.2019.

Copyright@ Jorge A De los Santos, This article is distributed under the terms of the Creative Commons Attribution 4.0 International License, which permits unrestricted use and redistribution provided that the original author and source are credited.

\author{
Jorge A De los Santos* \\ Department of Animal Science, Madison University, Wisconsin, USA
}

\section{Opinion}

A fascinating concept in biology, in my personal opinion, is how cells are able to make new cells expressing the information from genes to proteins all over the earth. From unicellular organisms, viruses, mycoplasma, protozoa, cancer cells, neurons to the most complex biological organisms and complex ecosystems, all of them rely on the gene expression. Darwin in his famous book "On the Origin of Species" in 1859, states that the species of organisms live and evolve through the natural selection processes. In 1976 Richard Dawkins states in his book "The Selfish Gene", that genes are the central piece in the way natural selection operates [1]. In this paper, I am going to explore the relationship between genes under the "selfish" rule and how these can inspire new technologies.

Genes are the smallest unit of information independent to each other. In fact, cell, organisms, and genomes particularly are mere vectors of the information carry on the genes. The immunological response that prevents microbial infections is based on the production of the antibodies. These proteins are produced by B-lymphocytes cells and encode in the DNA [2]. In fact, each of this cell produces a particular protein called antigen and involve the rearrangement of the genes in the cell. In order to produce and fight against the exogenous organisms the immunological system is able to constantly produce new variation of genes [3].

Genes that are able to match antigens, duplicate easily and expand under a cellular cloning process. Indeed, a vaccine is any substance that stimulates the production of antibodies [4] and provides immunity against microbial infections. In fact, these cells have different genomes. The immunological system produces clones of these cells when the antibody shows up more than one time in the body [5]. I consider this is another example of selection of the most adapted, where genes and cells are the central part of natural selection.

\section{Can we have some technological advances base on the selfish gene concept?}

Cancer disease is the uncontrolled expression of certain genes that produce the exacerbations of particulars biochemical pathways, for instance, phosphorylation of signaling proteins, and finally uncontrolled growing of cells shows up [6]. As well as cells B, cancer cells carrying the "best genes" are able to duplicate and expand easily than others. At the level of the organism, it is almost impossible that the immunological system reacts and fights against cancer cells because this is part of the same organism [4]. Therefore, it is remarkably hard to produce an immunological response. The use of bacteria to fight against cancer began in 1800 by William Coley. The idea is quite simple; bacteria attacks the cancer cell, and this produces an immunological reaction in the body which then can be identified as a threat [7]. Recently a researcher from Yale University deleted the lethal genes in Salmonella Typhimurium in order to attack cancer cells. Data from animals' models, phase I, provides interesting results [8]. However, the strain is not able to colonize human tumors in the clinical trials. It is not clear how and why the bacteria are able to kill the melanoma cells $[9,10]$. Despite this promissory data researchers argue that in humans their immunological system will rapidly destroy the bacteria before interacting with the cancer cells [11].

This is another example of the battle at the level of genes carried by cells and organisms in which the best genes will be able expand. The first vaccination was developed in England in 1796 against smallpox virus. In fact, the disease, not the virus, was eradicated in 1980 
according to the world health organization [12]. As I explained before the vaccine's technologies rely on the antibody productions, and only the B-cells with the best genes are able increase in number. The final goal is the microorganism attack. I think this is an example of vaccine technology base on the selfish gene principle. Viruses are not alive but operate under the selfish gene rules. In order to replicate viruses, need an alive cell [13]. The viral DNA takes the control of the cell in order to produce more viruses. So, there are also target of vaccinations scope, human papilloma virus is an examples of this.

\section{What can we learn from the selfish gene and how can we develop new biotechnological approaches?}

How can we use the selfish gene concept to tackle the most and relevant diseases that human face at the present time? Genes are immortal and they don't belong to an organism, they are able to jump and replicate in order to survive and produce more and more copies of themselves [14]. In fact, cancer and cloning of cells $B$ are examples of cell having the best genes. Some researchers take this idea to the edge. In order to create disruptive antibacterial technologies, another technological problems nowadays, they use circular DNA with independent origin of replication from the genomic bacterial, called plasmid and insert in host bacterial. The researcher boosted the replicator genes in the plasmid, so the cell lost the metabolic control and finally die. The most interesting fact is that this plasmid is able to jump from one cell to another acting as antimicrobial agent [15]. The technology was promising and was capable to support a patent and a startup company named ConjuGon. Scientific has been developed the production of antibodies in vegetables called edible vaccines. Another example of genes transported in exogenous cell able to be expanded. For instance, apples, bananas or even industrial product like yogurt or milk are able to carry antibodies that release an immunological respond. Comestible vaccines present technical advantages, in fact, a vaccine in a transgenic plant would evade transportation problem frozen demands and accessible in rural areas. Despite this, the biotechnological products have to be under the regulation scope so it will take time before reaching the market.

\section{Conclusion}

In biology science, there are always exceptions to generals' rules. From vaccination to the most advanced technologies and cancer disease, the selfish gene can explain the molecular principles behind the lethality of disease like cancer or vaccination approaches. Understanding the molecular and microorganisms' behavior will allow researchers better understand general rules in order to fight against diseases. I think it is important for resolving problems in biology understanding the fundamental rules behind molecular biology of gene expression. This would lead to reach better and new approaches and sustainability in long-term. As I have shown in this paper, genes are immortal and are the base of evolution that can inspire new technologies.

\section{References}

1. Richard Dawkins (1976) The selfish gene. Oxford University Press, UK.

2. Charles A Janeway J, Travers P, Walport M, Shlomchik MJ (2001). The rearrangement of antigen-receptor gene segments controls lymphocyte development. Immunobiology.

3. Wagener, Stocking, Müller (2017) Cancer Signaling. Wiley, Hoboken, New Jersey, United States

4. Nybo K (2018) Fighting cancer with deadly bacteria. Biotechniques 64(1): 6-8.

5. Toso JF, Gill VJ, Hwu P, Marincola FM, Restifo NP, et al. (2002) Phase I study of the intravenous administration of attenuated Salmonella typhimurium to patients with metastatic melanoma. J Clin Oncol Official 20(1): 142-152.

6. https://www.who.int/csr/disease/smallpox/en/

7. Filutowicz M, Burgess R, Gamelli RL, Heinemann JA, Kurenbach B, et al. (2008) Bacterial conjugation-based antimicrobial agents. Plasmid 60(1): 38-44.

8. https://patents.google.com/patent/US20040224340/en

9. Concha C, Cañas R, Macuer J, Torres MJ, Herrada AA, et al. (2017) Disease Prevention: an opportunity to expand edible plant-based vaccines? Vaccines 5(2): E14.

10. Lugade AA, Kalathil S, Heald JL, Thanavala Y (2010) Transgenic plantbased oral vaccines. Immunol Invest 39(4-5): 468-482.

11. Wood DJ (2002) New vaccine technologies. Dev Biol 111: 285-290.

12. Spier RE (2001) Perception of risk of vaccine adverse events: a historical perspective. Vaccine 20 Suppl (1): S75-84.

13. Shiv Pillai AK, Abul A, Andrew H (2015) Basic Immunology ( $5^{\text {th }}$ Edn).

14. Felgner S, Kocijancic D, Frahm M, Curtiss R, Erhardt M, et al. (2016) Optimizing Salmonella enterica serovar Typhimurium for bacteriamediated tumor therapy. Gut Microbes 7(2): 171-177.

15. https://www.cdc.gov/vaccines/vpd/vaccines-list.html 